\title{
On the feasibility to perform integral transmission experiments in the GELINA target hall at IRMM
}

\author{
Pierre Leconte ${ }^{1, a}$, Cyrille De Saint Jean ${ }^{1}$, Benoit Geslot ${ }^{2}$, Arjan Plompen ${ }^{3}$, Francesca Belloni ${ }^{3}$, Markus Nyman ${ }^{3}$ \\ ${ }^{1}$ CEA Cadarache, DEN/CAD/DER/SPRC/LEPh, 13108 Saint Paul Lez Durance Cedex, France \\ ${ }^{2}$ CEA Cadarache, DEN/CAD/DER/SPEx/LPE, 13108 Saint Paul Lez Durance Cedex, France \\ ${ }^{3} J R C-I R M M$, Geel, Belgium
}

\begin{abstract}
Shielding experiments are relevant to validate elastic and inelastic scattering cross sections in the fast energy range. In this paper, we are focusing on the possibility to use the pulsed white neutron time-of-flight facility GELINA to perform this kind of measurement. Several issues need to be addressed: neutron source intensity, room return effect, distance of the materials to be irradiated from the source, and the sensitivity of various reaction rate distributions through the material to different input cross sections. MCNP6 and TRIPOLI4 calculations of the outgoing neutron spectrum are compared, based on electron/positron/gamma/neutron simulations. A first guess of an integral transmission experiment through a ${ }^{238} \mathrm{U}$ slab is considered. It shows that a $10 \mathrm{~cm}$ thickness of uranium is sufficient to reach a high sensitivity to the ${ }^{238} \mathrm{U}$ inelastic scattering cross section in the [2-5 MeV] energy range, with small contributions from elastic and fission cross sections. This experiment would contribute to reduce the uncertainty on this nuclear data, which has a significant impact on the power distribution in large commercial reactors. Other materials that would be relevant for the ASTRID $4^{\text {th }}$ generation prototype reactor are also tested, showing that a sufficient sensitivity to nuclear data would be obtained by using a 50 to $100 \mathrm{~cm}$ thick slab of side $60 x 60 \mathrm{~cm}$. This study concludes on the feasibility and interest of such experiments in the target hall of the GELINA facility.
\end{abstract}

\section{Introduction}

Shielding experiments concern the measurement of neutron and gamma flux attenuation through large thicknesses of material, using either point-like sources ${ }^{252} \mathrm{Cf}$ for instance) or neutron beams from test reactors. Most of these experiments were initially driven by the need to validate calculation codes related to radiation protection. They also have an interest for nuclear data evaluators as they provide a convenient way to validate neutron inelastic scattering cross sections which are often difficult to measure by differential experiments.

SINBAD [1] is an international effort to store, evaluate and share shielding experiments that were made by fourteen different countries, among them USA, Russia, UK and France. Materials covered include air, graphite, concrete, $\mathrm{N}, \mathrm{O}, \mathrm{H}_{2} \mathrm{O}, \mathrm{Al}, \mathrm{Be}, \mathrm{Cu}, \mathrm{C}, \mathrm{Fe}, \mathrm{Pb}, \mathrm{Li}$, $\mathrm{Ni}, \mathrm{Nb}, \mathrm{SiC}, \mathrm{Na}$, Stainless Steel, W and V. Most of these experiments are more than thirty years old and not all of them have the sufficient quality assurance to be used for nuclear data validation. Moreover, the list of materials does not include heavier materials than tungsten. Uranium 238 for instance belongs to a high priority request list at OECD/NEA to improve the inelastic scattering cross section, due to its major impact on both thermal and fast reactor estimates. Indeed, a paper published at the PHYSOR conference [2] showed that the a priori uncertainty on the radial power map for LWR-

\footnotetext{
${ }^{\mathrm{a}}$ Corresponding author: pierre.leconte@cea.fr
}

UOx cores (and its swing between the center and the periphery) is $5-6 \%(1 \sigma)$.

This is why CEA and IRMM have considered the possibility to perform new shielding experiments to meet the target accuracies which are required for reactor physics studies (typically less than $5 \%$ at $1 \sigma$ ). Such an experiment was recently performed in the CALIBAN critical facility at Valduc [3], in the framework of collaboration between CEA/DEN (Nuclear Energy Division) and CEA/DAM (Military Application Division).

In this paper, we are considering the feasibility of using the pulsed white neutron source GELINA, located at Geel in Belgium, to perform shielding experiments within the target hall. Firstly, we present comparisons of MCNP6 and TRIPOLI4 calculations of the outgoing neutron source, generated by the slowing down of 70-150 $\mathrm{MeV}$ electrons within the depleted Uranium target. Secondly, we present the main characteristics of the neutron flux at 70 to $120 \mathrm{~cm}$ from the source. Thirdly, we present preliminary calculations of a transmission experiment based on several disks of depleted Uranium available at IRMM and the use of several activation dosimeters based on threshold reactions. Finally, some quantitative results are presented for the measurement of other materials of interest for the ASTRID $4^{\text {th }}$ generation prototype reactor: iron, sodium and magnesium oxide. 


\section{Monte-Carlo calculation of the GELINA neutron source}

The MCNP input file of GELINA was provided by IRMM and is described in Ref. [4]. An equivalent model was built for TRIPOLI4. It consists of a mono-directional electron beam, with homogeneously distributed energies from 70 to $140 \mathrm{MeV}$, reaching a depleted Uranium torus, cooled by a mercury flow. The electron slowing down produces high energy bremsstrahlung photons which generate neutrons by $(\gamma, n),(\gamma, x n)$ and $(\gamma, f)$ reactions. A scheme of the accelerator and target hall is presented in Figure 1.

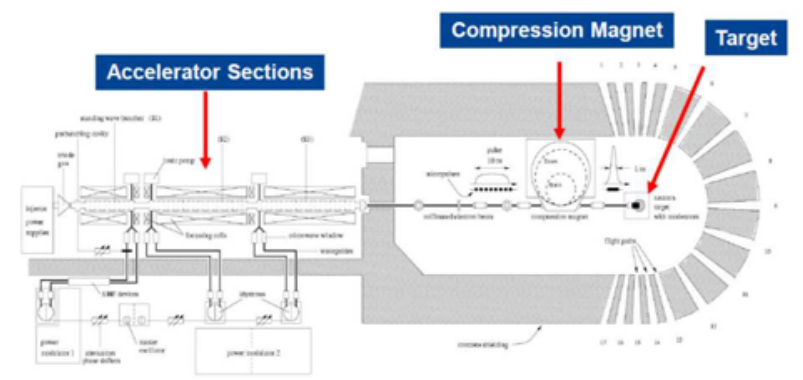

Figure 1. The GELINA electron accelerator

For this simulation, four types of particle are followed: electrons, positrons, gammas, and neutrons. In this first step, the environment of the electron gun was not included in the model, as the purpose of this calculation is only to get the source term. The calculated neutron spectrum is illustrated in Figure 2. It is compared to the neutron spectrum that was calculated for the CALIBAN experiment [3].

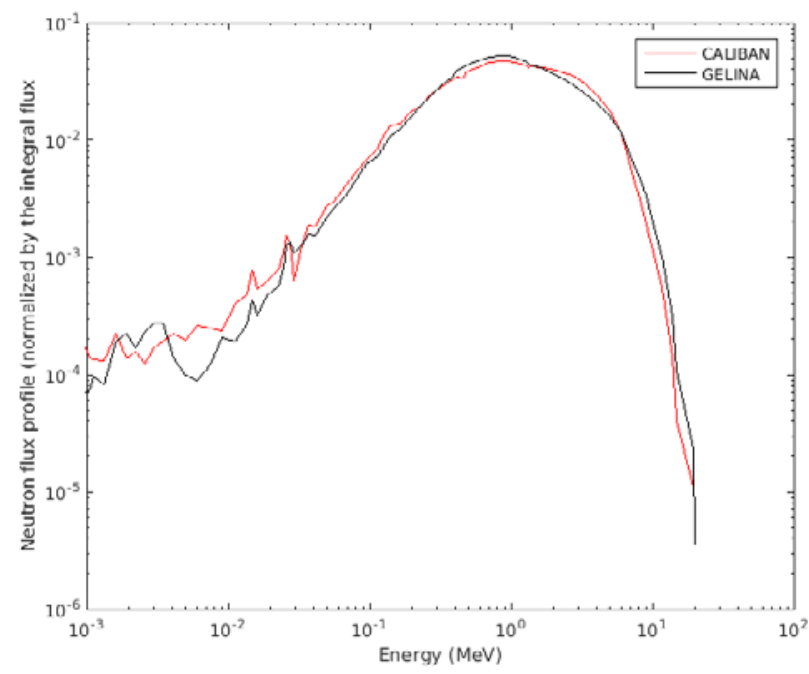

Figure 2. MCNP6 calculation of the neutron flux spectrum in GELINA, compared with the neutron spectrum from the CALIBAN critical facility.

The GELINA spectrum matches the one from CALIBAN very well in the fast energy range. The maximum neutron emission rate in GELINA is $3.210^{13} \mathrm{n} / \mathrm{s}$. It is equivalent to a $300 \mathrm{~W}$ irradiation in CALIBAN (maximum allowed is $1 \mathrm{~kW})$.

An equivalent TRIPOLI4 input file of GELINA was prepared as well, in order to cross check the two codes, based on the same nuclear data for neutrons, photons and electrons. The comparison of neutron spectra is showed on the Figure 3. No significant difference can be observed in the fast energy range between the two codes, except a slightly harder shape in the energy range above $10 \mathrm{MeV}$ for MCNP6. The change from ENDF/B-VII.1 nuclear data file to JEFF-3.2 does not have any impact, except in the lower part of the spectrum, below $10 \mathrm{keV}$ where the slowing down contribution has almost a one order magnitude difference between two libraries. It should be noticed also that the MCNP spectrum has a smoother shape in this region than the TRIPOLI one, a difference that is still under investigation.

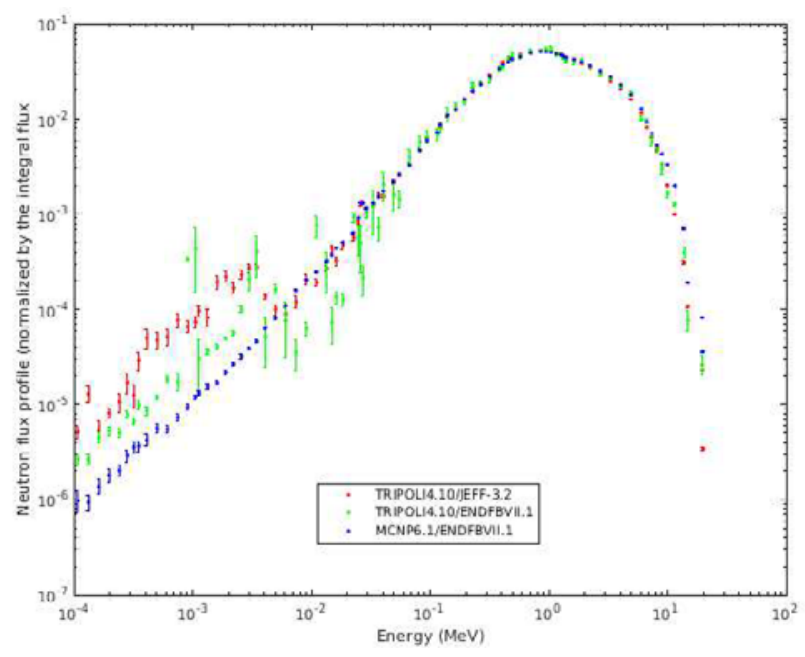

Figure 3. MCNP6.1 vs TRIPOLI4.10 calculation of the neutron flux spectrum in GELINA at the U disk position.

\section{Characterization of the neutron flux within the target hall}

The simulated neutron flux is used in a second step as an input source in a TRIPOLI calculation where the environment of the target hall is taken into account. The geometry is described in a rather simple way: only the concrete walls are modelled, as they should be the highest contributor to the thermal neutron background due to the scattering on light elements $\left(\mathrm{H}_{2} \mathrm{O}, \mathrm{Si}, \mathrm{Ca} \ldots\right)$. The neutron flux is calculated at several distances from the target and is characterized in terms of amplitude and energy spectrum. Figure 4 illustrates calculated neutron flux for three distances from the target: 40,70 and $100 \mathrm{~cm}$.

One can notice that the thermal neutron background is independent of the distance from the source, while the fast neutron component is approximatively decreasing by $1 / d^{2}$, with $d$ the distance from the target. As a consequence, to prevent the influence of thermal background, the material to be irradiated should be positioned as close to the target as reasonably achievable, to maximize the fast over thermal ratio. The main issue 
when reducing the distance is linked to the dose rate of operators who will prepare the device and retrieve the activated dosimeters after the irradiation. A compromise will have to be found to satisfy both aspects. Some tests are currently ongoing to evaluate the dose rate within the target hall. A short time irradiation of gold, indium, nickel and rhodium foils will be prepared either to evaluate the expected activity, in order to prepare more accurate design calculations.

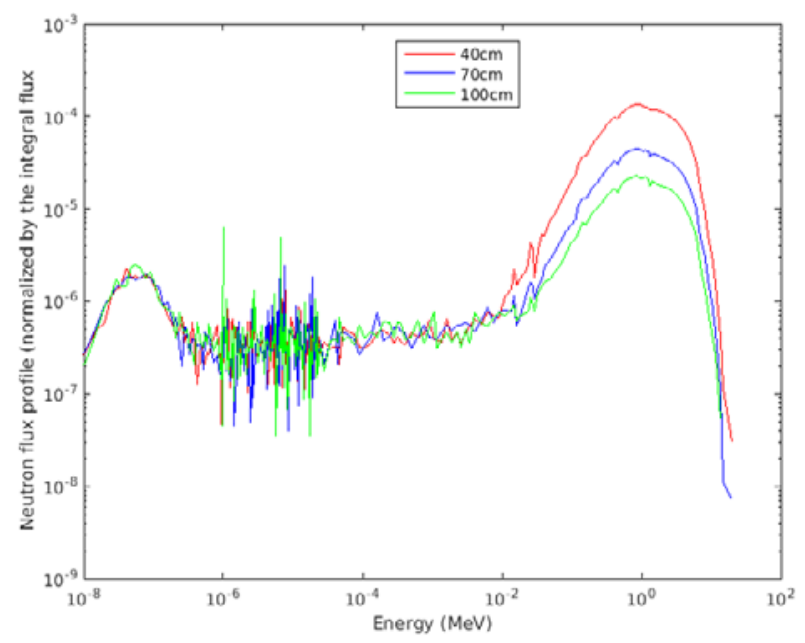

Figure 4. TRIPOLI4 neutron flux for several distances from the Uranium target.

\section{Feasibility of an integral transmission experiment through a Uranium slab}

We have tested the possibility and the interest of an integral transmission experiment through a set of different depleted Uranium disks (see Figure 5).

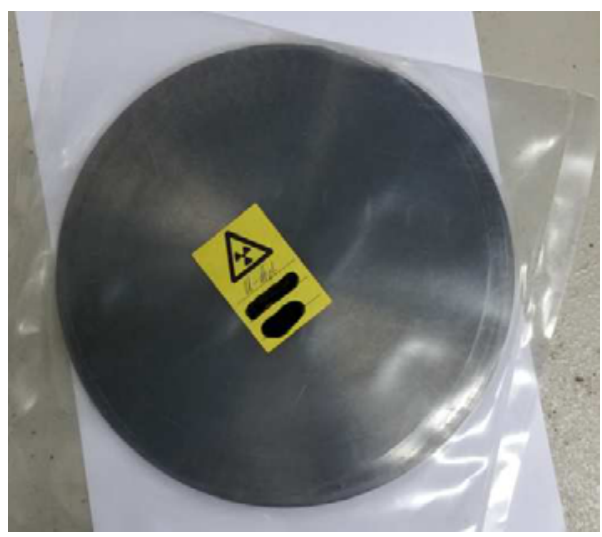

Figure 5. Depleted Uranium disks available at IRMM

The disks have a diameter of $21 \mathrm{~cm}$ and various thicknesses of 0.5 to $2 \mathrm{~cm}$. They can be piled to build a cylinder of total thickness $15 \mathrm{~cm}$, interleaved with $\mathrm{Al}$ sheets for containment and dosimeter holders. $\gamma$ spectrometry measurements were performed on one of them in order to record the $186 \mathrm{keV}$ and $1001 \mathrm{keV}$ peaks corresponding respectively to ${ }^{235} \mathrm{U}$ and ${ }^{238} \mathrm{U}$ decay. The ${ }^{235} \mathrm{U}$ mass enrichment of the disk was found to be $(0.264 \pm 0.012) \%(1 \sigma)$.
Calculations were performed to evaluate the integral transmission of the neutron flux, using various threshold dosimeters. For this study, we have considered a mean distance of $100 \mathrm{~cm}$ from the source but the conclusions should not be changed if we revise this value. We present the results hereafter.

\subsection{Integral transmission coefficients $T$}

Firstly, we evaluate the integral transmission coefficient $T(x)$ which is defined as follows:

$$
T(x)=\mathrm{R}(x) / \mathrm{R}(0)
$$

where $\mathrm{R}(x)$ defines the microscopic activation rate on the dosimeter placed behind a thickness of Uranium $\Delta x$ and $\mathrm{R}(0)$ is the microscopic activation rate on the dosimeter placed on the front size of the Uranium slab.

Table 1 presents the calculated coefficients for three kinds of threshold reactions (E50\% represents the energy corresponding to half of the total reaction rate in a pure ${ }^{252} \mathrm{Cf}$ spectrum). They have been obtained with TRIPOLI4.9 and the JEFF-3.1.1 nuclear data library. For a qualitative appreciation of the influence of the room return effect, we have computed the same transmission coefficients without the concrete walls of the target hall.

Table 1. Integral transmission coefficients for different threshold dosimeters and different penetration length (uncertainties are given at $1 \sigma$ )

\begin{tabular}{|c|c|c|c|c|}
\hline \multirow{2}{*}{$\begin{array}{l}\text { Threshold } \\
\text { reaction }\end{array}$} & \multirow{2}{*}{$\mathrm{E} 50 \%$} & \multirow{2}{*}{$\begin{array}{c}x \\
(\mathrm{~cm})\end{array}$} & \multicolumn{2}{|c|}{ Integral transmission coefficient $T(x)$} \\
\hline & & & $\begin{array}{l}\text { Geometry with } \\
\text { concrete walls }\end{array}$ & $\begin{array}{c}\text { Geometry without } \\
\text { concrete walls }\end{array}$ \\
\hline \multirow{5}{*}{${ }^{115} \operatorname{In}\left(\mathrm{n}, \mathrm{n}^{\prime}\right)$} & \multirow{5}{*}{2.7} & 3 & $0.620 \pm 0.017$ & $0.645 \pm 0.005$ \\
\hline & & 6 & $0.350 \pm 0.011$ & $0.351 \pm 0.003$ \\
\hline & & 9 & $0.192 \pm 0.017$ & $0.184 \pm 0.002$ \\
\hline & & 12 & $0.105 \pm 0.015$ & $0.091 \pm 0.001$ \\
\hline & & 15 & $0.073 \pm 0.004$ & $0.043 \pm 0.001$ \\
\hline \multirow{5}{*}{${ }^{54} \mathrm{Fe}(\mathrm{n}, \mathrm{p})$} & \multirow{5}{*}{4.3} & 3 & $0.600 \pm 0.025$ & $0.631 \pm 0.008$ \\
\hline & & 6 & $0.339 \pm 0.016$ & $0.355 \pm 0.005$ \\
\hline & & 9 & $0.196 \pm 0.012$ & $0.192 \pm 0.003$ \\
\hline & & 12 & $0.105 \pm 0.008$ & $0.102 \pm 0.002$ \\
\hline & & 15 & $0.063 \pm 0.006$ & $0.052 \pm 0.002$ \\
\hline \multirow{5}{*}{${ }^{24} \mathrm{Mg}(\mathrm{n}, \mathrm{p})$} & \multirow{5}{*}{8.3} & 3 & $0.617 \pm 0.051$ & $0.629 \pm 0.051$ \\
\hline & & 6 & $0.338 \pm 0.031$ & $0.383 \pm 0.058$ \\
\hline & & 9 & $0.213 \pm 0.029$ & $0.211 \pm 0.033$ \\
\hline & & 12 & $0.115 \pm 0.018$ & $0.123 \pm 0.063$ \\
\hline & & 15 & $0.051 \pm 0.011$ & $0.070 \pm 0.006$ \\
\hline
\end{tabular}

The dependence of transmission coefficients with $\Delta \mathrm{x}$ is very close to an exponential function $\exp (-\mathrm{a} x)$, which is consistent with the H. Bethe empirical formulation [5]. The influence of concrete walls is only significant for transmission with $x=15 \mathrm{~cm}$, as the relative abundance of slowing down neutrons become significant, compared to the low transmission rate of fast neutrons. Moreover, as it is very unlikely that scattered neutrons could have high energies, the wall return effect will decrease with the activation threshold. To mitigate this issue, it is planned to add a $0.5 \mathrm{~cm}$ disk at the back side of the $15 \mathrm{~cm}$ 
cylinder. Acting as a shield to the thermal neutron background, it would significantly reduce the call return contribution, especially for the low energy dosimeters.

\subsection{Sensitivity of integral transmission coefficients to ${ }^{238} \mathrm{U}$ partial cross sections}

Secondly we have computed integral sensitivity coefficients to evaluate how the transmission coefficients will be related to reaction cross sections. Three reactions have been tested by changing three different input cross sections by $1 \%$ over the full energy range: elastic, total inelastic (continuum + discrete) and fission. Preliminary calculations have showed that other reactions (i.e. radiative capture and $(\mathrm{n}, \mathrm{xn})$ reactions) can be neglected.

To do so, we have used the correlated sampling method [6][7] in TRIPOLI4 which evaluates the change in reaction rates thanks to a modified weight, according to the change in the cross section.

Table 2 gives the sensitivity coefficients $S\left(\sigma_{\mathrm{i}}, \Delta x\right)$ defined as follows:

$$
S\left(\sigma_{\mathrm{i},} \Delta x\right)=[\delta T(\Delta x) / T(\Delta x)] /\left[\delta \sigma_{\mathrm{i}} / \sigma_{\mathrm{i}}\right]
$$

The absolute uncertainty is typically \pm 0.05 on $S\left(\sigma_{\mathrm{el}}, \Delta x\right)$, \pm 0.02 on $S\left(\sigma_{\text {inel, }} \Delta x\right)$ and $S\left(\sigma_{\mathrm{f},} \Delta x\right)$.

Table 2. Sensitivity coefficients of transmission coefficients $T$ to different ${ }^{238} \mathrm{U}$ cross section

\begin{tabular}{|c|c|c|c|c|c|}
\hline \multirow{2}{*}{$\begin{array}{l}\text { Threshold } \\
\text { reaction }\end{array}$} & \multirow{2}{*}{$\mathrm{E} 50 \%$} & \multirow{2}{*}{$\begin{array}{c}\Delta x \\
(\mathrm{~cm})\end{array}$} & \multicolumn{3}{|c|}{$S\left(\sigma_{\mathrm{i}}, \Delta x\right)$} \\
\hline & & & $\begin{array}{c}\text { Elastic } \\
\text { scattering }\end{array}$ & $\begin{array}{c}\text { Total } \\
\text { inelastic }\end{array}$ & Fission \\
\hline \multirow{5}{*}{${ }^{115} \operatorname{In}\left(\mathrm{n}, \mathrm{n}^{\prime}\right)$} & \multirow{5}{*}{2.7} & 3 & 0.03 & -0.36 & -0.09 \\
\hline & & 6 & -0.04 & -0.77 & -0.16 \\
\hline & & 9 & -0.16 & -1.13 & -0.25 \\
\hline & & 12 & -0.26 & -1.39 & -0.30 \\
\hline & & 15 & -0.42 & -0.99 & -0.21 \\
\hline \multirow{5}{*}{${ }^{54} \mathrm{Fe}(\mathrm{n}, \mathrm{p})$} & \multirow{5}{*}{4.3} & 3 & -0.03 & -0.29 & -0.11 \\
\hline & & 6 & -0.08 & -0.63 & -0.21 \\
\hline & & 9 & -0.14 & -0.97 & -0.34 \\
\hline & & 12 & -0.25 & -1.24 & -0.41 \\
\hline & & 15 & -0.45 & -1.11 & -0.34 \\
\hline \multirow{5}{*}{${ }^{24} \mathrm{Mg}(\mathrm{n}, \mathrm{p})$} & \multirow{5}{*}{8.3} & 3 & -0.11 & -0.07 & -0.16 \\
\hline & & 6 & -0.22 & -0.26 & -0.29 \\
\hline & & 9 & -0.09 & -0.38 & -0.49 \\
\hline & & 12 & -0.20 & -0.56 & -0.57 \\
\hline & & 15 & -0.38 & -0.66 & -0.65 \\
\hline
\end{tabular}

For threshold reactions occurring in the $[2-5 \mathrm{MeV}]$ energy range, the sensitivity coefficient mostly depends on the plateau value of the inelastic scattering cross section. The optimal compromise between room return effect and the relative contributions of elastic and fission cross sections is 9 or $12 \mathrm{~cm}$ attenuation where the inelastic is 3-10 times higher than other reaction. For reactions occurring at higher energies than $5 \mathrm{MeV}$ where the fission cross section increases while the inelastic decreases, the sensitivity becomes equivalent between the two reactions. The uncertainty of the fission cross section is $<1 \%$, so that $\mathrm{C} / \mathrm{E}$ differences are expected to reflect differences in inelastic cross section [8].
Based on these preliminary results, a project proposal have been submitted in June 2016 and accepted by the EUFRAT PAC (European facility for nuclear reaction and decay data measurements) for a one week experiment on ${ }^{238} \mathrm{U}$ scheduled in September 2016.

\section{Application for other materials: $\mathrm{Fe}, \mathrm{Na}$ and $\mathrm{MgO}$}

Iron, Sodium and Magnesium Oxide are other relevant materials for the ASTRID $4^{\text {th }}$ generation prototype reactor: they are respectively used in assemblies and claddings, for the fuel cooling and to prevent radial leakage to preserve the core vessel. In the fast energy regions, elastic and inelastic scattering cross sections are important nuclear data to validate for design calculations. Moreover, covariance matrices, which are required for uncertainty analysis, are missing for ${ }^{16} \mathrm{O}$ and ${ }^{24} \mathrm{Mg}$ in the current JEFF-3.2 library.

In this framework, we have investigated the possibility of using large blocks of these materials within the target hall of GELINA, in order to make integral transmission measurements as well. For the block dimension definition, one of our constraints was to adapt the block to the support table that has been manufactured for the experiment on ${ }^{238} \mathrm{U}$ : the maximum material size was imposed to be a rectangular block of maximum $60 \times 60 \times 200 \mathrm{~cm}$ (largest dimension in the direction towards the source). The positions for computing the activation rates are the following ones: $0,5,10,15,20,25,30,40$, $50,60,70,80,100,120,140,160,180$ and $200 \mathrm{~cm}(0 \mathrm{~cm}$ being the front side position inside the block). The list of dosimeters is : ${ }^{103} \mathrm{Rh}\left(\mathrm{n}, \mathrm{n}^{\prime}\right), \quad{ }^{115} \mathrm{In}\left(\mathrm{n}, \mathrm{n}^{\prime}\right), \quad{ }^{58} \mathrm{Ni}(\mathrm{n}, \mathrm{p})$, ${ }^{24} \operatorname{Mg}(\mathrm{n}, \mathrm{p})$.

A general scheme is represented in Fig.6 (the actual scale is not respected).

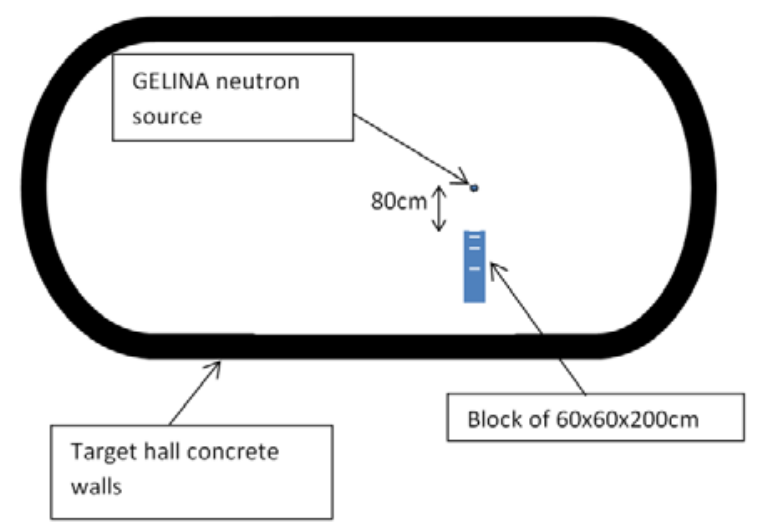

Figure 6. Scheme of the GELINA target hall with the block of material to be investigated

\subsection{Results for $\mathrm{Na}$}

We are representing hereafter the relative activation rate distribution within a pure sodium block of 60x60×200 cm (Figure 7) and the sensitivity coefficients for the ${ }^{103} \mathrm{Rh}(\mathrm{n}$, inel $),{ }^{115} \mathrm{In}(\mathrm{n}$, inel $),{ }^{58} \mathrm{Ni}(\mathrm{n}, \mathrm{p})$ and ${ }^{24} \mathrm{Mg}(\mathrm{n}, \mathrm{p})$ threshold reactions (Figures 8 to 11 ). 


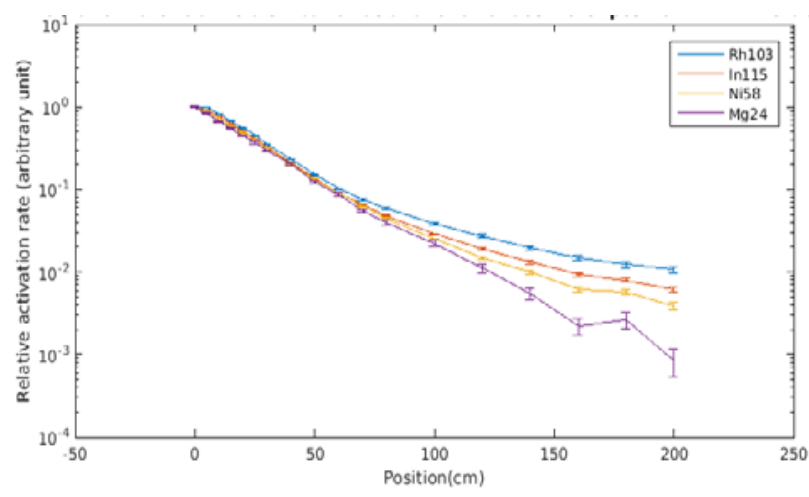

Figure 7. Activation rate relative distribution as a function of dosimeter position within the sodium block

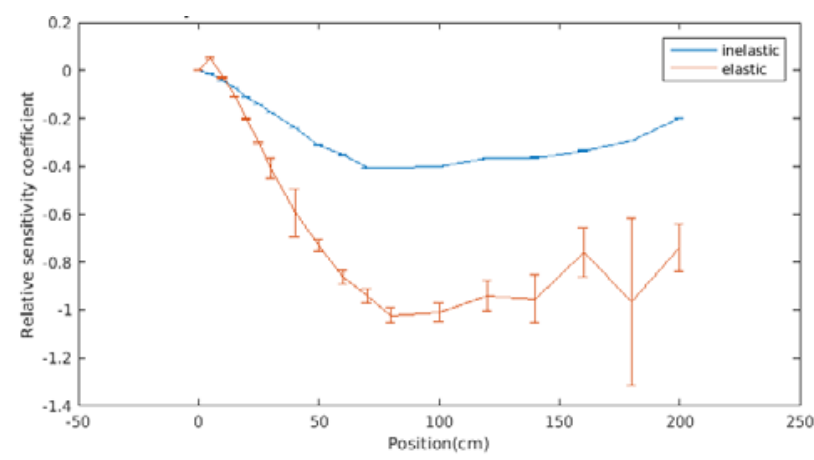

Figure 8. Sensitivity coefficients of the integral transmission rate of ${ }^{103} \mathrm{Rh}\left(\mathrm{n}, \mathrm{n}\right.$ ') for the ${ }^{23} \mathrm{Na}$ scattering cross sections

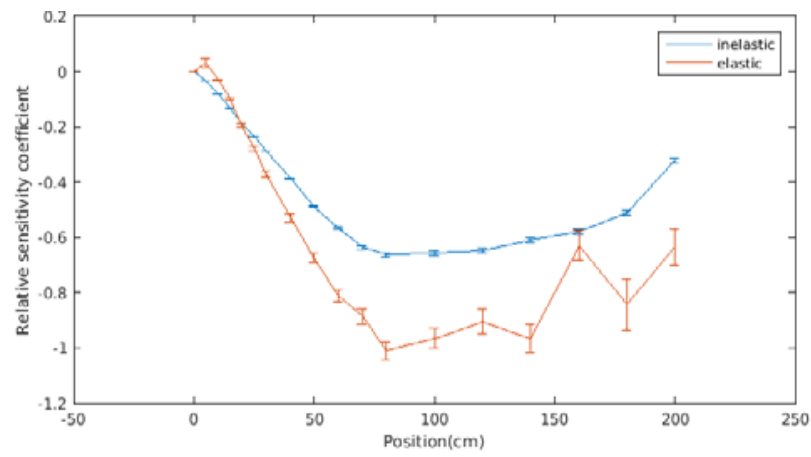

Figure 9. Sensitivity coefficients of the integral transmission rate of ${ }^{115} \operatorname{In}\left(\mathrm{n}, \mathrm{n}^{\prime}\right)$ for the ${ }^{23} \mathrm{Na}$ scattering cross sections

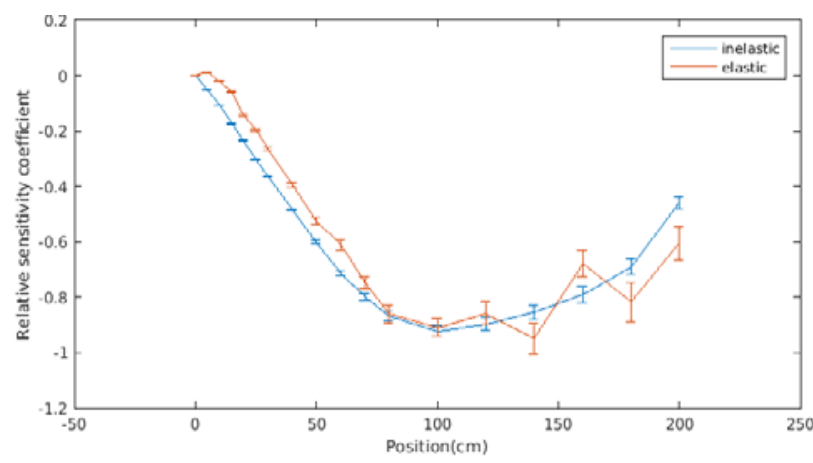

Figure 10. Sensitivity coefficients of the integral transmission rate of ${ }^{58} \mathrm{Ni}(\mathrm{n}, \mathrm{p})$ for the ${ }^{23} \mathrm{Na}$ scattering cross sections

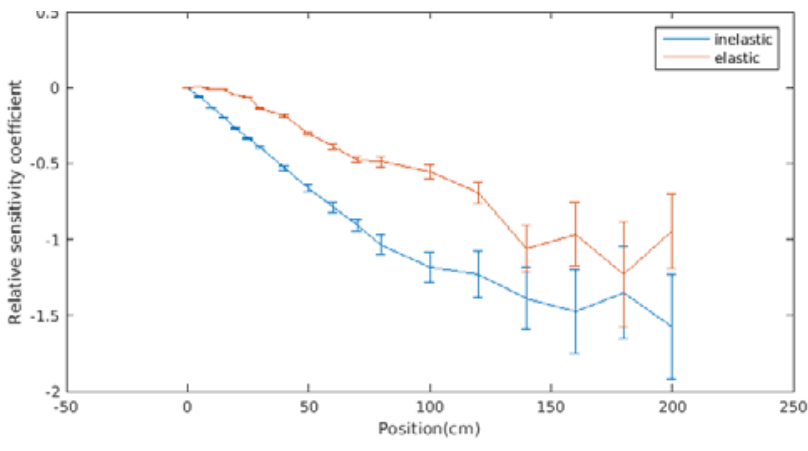

Figure 11. Sensitivity coefficients of the integral transmission rate of ${ }^{24} \mathrm{Mg}(\mathrm{n}, \mathrm{p})$ for the ${ }^{23} \mathrm{Na}$ scattering cross sections

The lowest transmission rates vary from $10^{-3}$ to $10^{-2}$ depending on the E50\% threshold energy of the dosimeter. The shape is roughly linear in log-scale for positions below $60 \mathrm{~cm}$.

Sensitivity coefficients are increasing almost linearly from 0 to $80 \mathrm{~cm}$ then they all tend to a saturated value above $100 \mathrm{~cm}$. The breakdown between the elastic and inelastic contributions of ${ }^{23} \mathrm{Na}$ shows the first one is dominant for low energy reactions $(\mathrm{Rh})$, while the second one becomes dominant for high energy reactions $(\mathrm{Mg})$.

Based on these different elements, a maximum thickness of $100 \mathrm{~cm}$ seems to be the best compromise for an integral transmission experiment with this material.

\subsection{Results for Fe}

We are representing hereafter the relative activation rate distribution within a pure iron block of $60 \times 60 \times 200 \mathrm{~cm}$ (Figure 12) and the sensitivity coefficients for the ${ }^{103} \mathrm{Rh}\left(\mathrm{n}\right.$, inel), ${ }^{115} \mathrm{In}(\mathrm{n}$, inel $), \quad$ and ${ }^{24} \mathrm{Mg}(\mathrm{n}, \mathrm{p})$ threshold reactions (Figures 13 to 16).

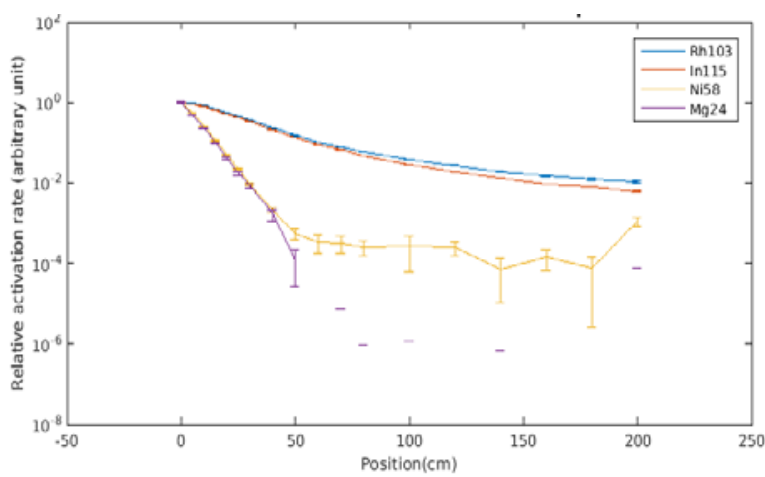

Figure 12. Activation rate relative distribution as a function of dosimeter position within the iron block 


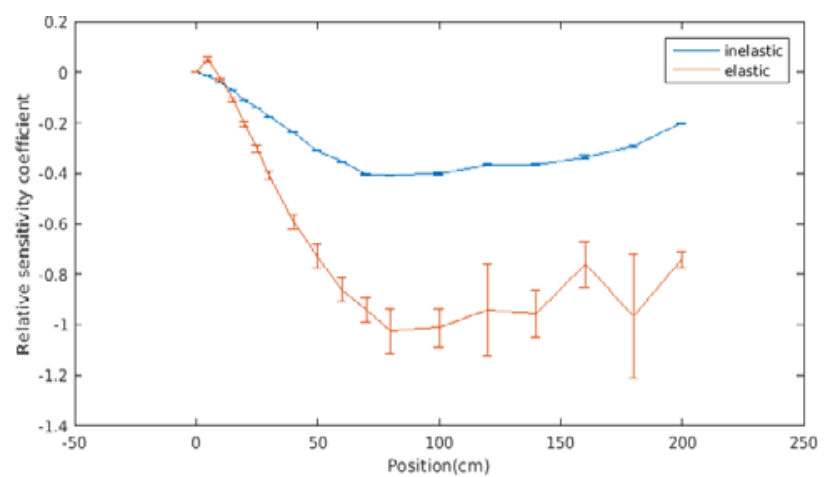

Figure 13. Sensitivity coefficients of the integral transmission rate of ${ }^{103} \mathrm{Rh}\left(\mathrm{n}, \mathrm{n}^{\prime}\right)$ for the ${ }^{56} \mathrm{Fe}$ scattering cross sections

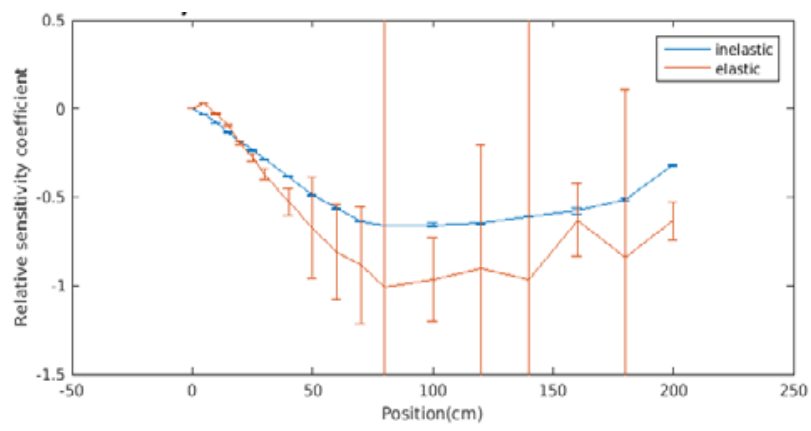

Figure 14. Sensitivity coefficients of the integral transmission rate of ${ }^{115} \operatorname{In}\left(\mathrm{n}, \mathrm{n}^{\prime}\right)$ for the ${ }^{56} \mathrm{Fe}$ scattering cross section

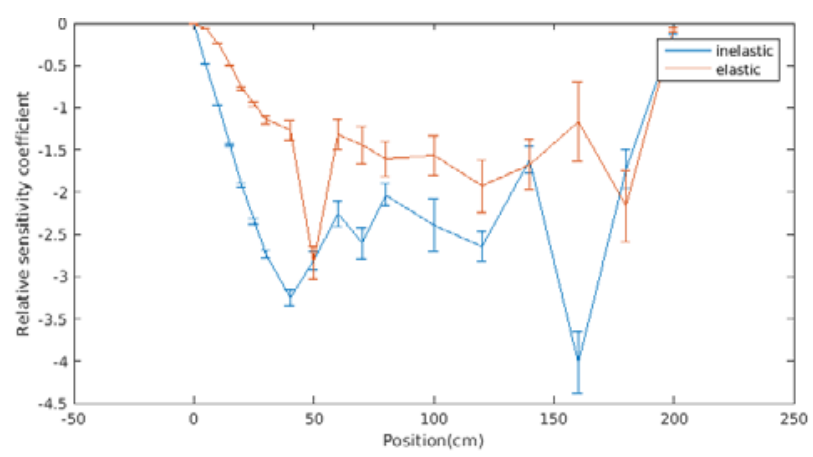

Figure 15. Sensitivity coefficients of the integral transmission rate of ${ }^{58} \mathrm{Ni}(\mathrm{n}, \mathrm{p})$ for the ${ }^{56} \mathrm{Fe}$ scattering cross sections

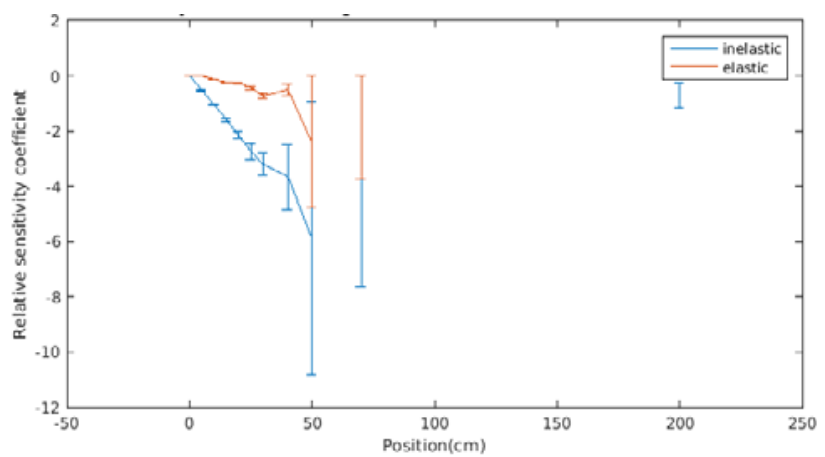

Figure 16. Sensitivity coefficients of the integral transmission rate of ${ }^{24} \mathrm{Mg}(\mathrm{n}, \mathrm{p})$ for the ${ }^{56} \mathrm{Fe}$ scattering cross sections

The lowest transmission rates vary from $10^{-4}$ to $10^{-2}$ depending on the E50\% threshold energy of the dosimeter. The shape is roughly linear in log-scale for positions below $60 \mathrm{~cm}$.
Sensitivity coefficients are increasing almost linearly from 0 to $80 \mathrm{~cm}$ for $\mathrm{Rh}$ and In, but only from 0 to $40 \mathrm{~cm}$ for $\mathrm{Ni}$ and $\mathrm{Mg}$, then they all tend to a saturated value. The breakdown between the elastic and inelastic contributions of ${ }^{56} \mathrm{Fe}$ shows the first one is dominant for low energy reactions $(\mathrm{Rh})$, while the second one becomes dominant for high energy reactions $(\mathrm{Mg})$.

Based on these different elements, a maximum thickness of $50 \mathrm{~cm}$ seems to be the best compromise for an integral transmission experiment with this material.

\subsection{Results for $\mathrm{MgO}$}

We are representing hereafter the relative activation rate distribution within a pure magnesium oxide block of $60 \times 60 \times 200 \mathrm{~cm}$ (Figure 17) and the sensitivity coefficients for ${ }^{103} \mathrm{Rh}(\mathrm{n}$, inel $),{ }^{115} \mathrm{In}(\mathrm{n}$, inel $),{ }^{58} \mathrm{Ni}(\mathrm{n}, \mathrm{p})$ and ${ }^{24} \mathrm{Mg}(\mathrm{n}, \mathrm{p})$ threshold reactions (Figures 18 to 21 ).

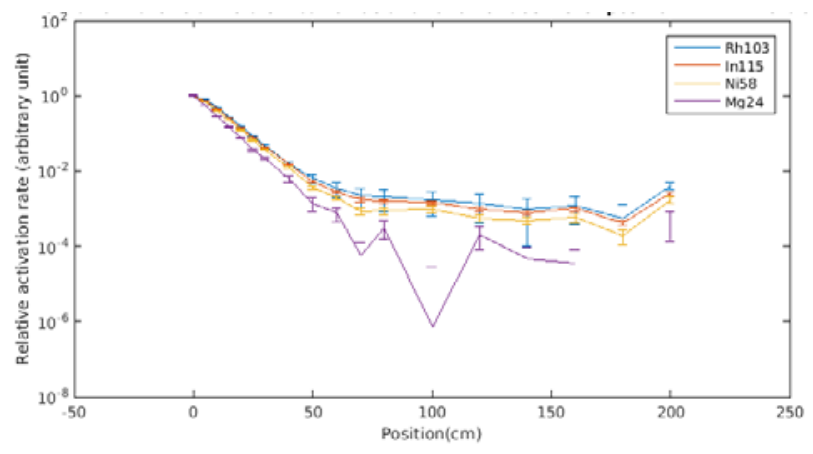

Figure 17. Activation rate relative distribution as a function of dosimeter position within the magnesium oxide block

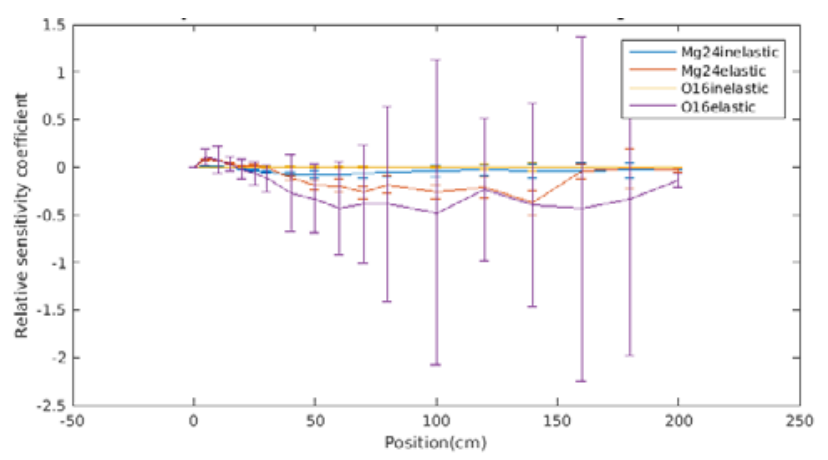

Figure 18. Sensitivity coefficients of the integral transmission rate of ${ }^{103} \mathrm{Rh}\left(\mathrm{n}, \mathrm{n}^{\prime}\right)$ for the $\mathrm{Mg}$ and $\mathrm{O}$ scattering cross sections

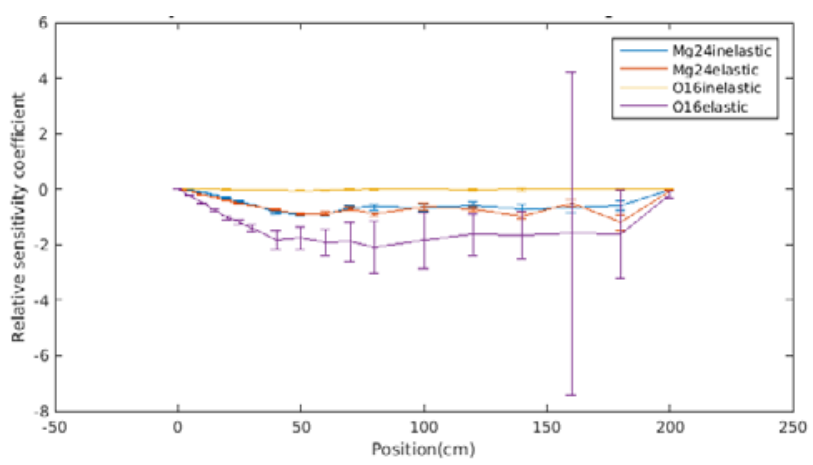

Figure 19. Sensitivity coefficients of the integral transmission rate of ${ }^{115} \operatorname{In}\left(\mathrm{n}, \mathrm{n}^{\prime}\right)$ for the $\mathrm{Mg}$ and $\mathrm{O}$ scattering cross sections 


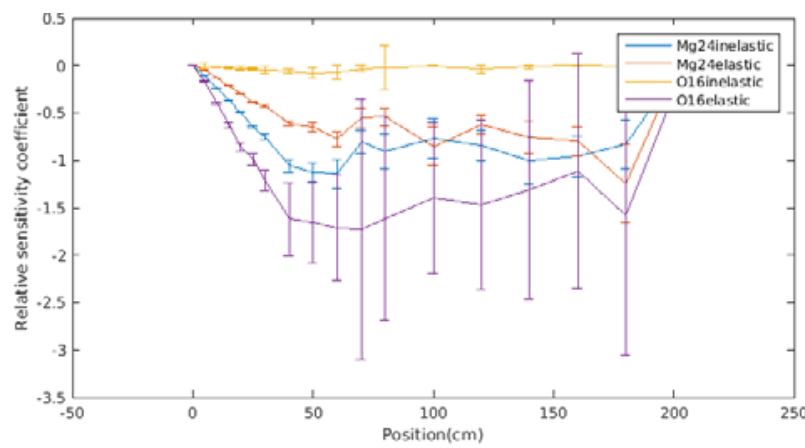

Figure 20. Sensitivity coefficients of the integral transmission rate of ${ }^{58} \mathrm{Ni}(\mathrm{n}, \mathrm{p})$ for the $\mathrm{Mg}$ and $\mathrm{O}$ scattering cross sections

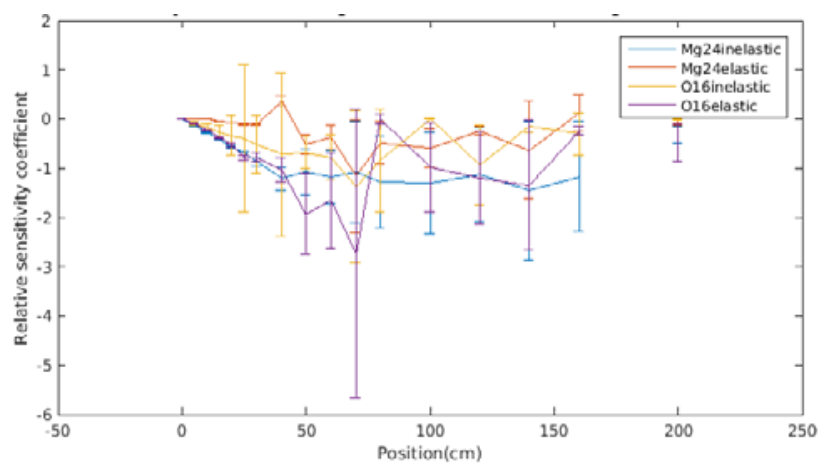

Figure 21. Sensitivity coefficients of the integral transmission rate of ${ }^{24} \mathrm{Mg}(\mathrm{n}, \mathrm{p})$ for the $\mathrm{Mg}$ and $\mathrm{O}$ scattering cross sections

The lowest transmission rate varies from $10^{-4}$ to $10^{-2}$ depending on the E50\% threshold energy of the dosimeter. The shape is roughly linear in log-scale for positions below $50 \mathrm{~cm}$.

Sensitivity coefficients are increasing almost linearly from 0 to $50 \mathrm{~cm}$ then they all tend to a saturated value. The sensitivity breakdown reveals a major contribution of ${ }^{16} \mathrm{O}$ elastic scattering, followed by ${ }^{24} \mathrm{Mg}$ elastic and inelastic scattering. Sensitivities reach a maximum for thickness of about $50 \mathrm{~cm}$.

Based on these different elements, a maximum thickness of $50 \mathrm{~cm}$ seems to be the best compromise for an integral transmission experiment with this material.

\section{Conclusions}

Preliminary calculations were performed to assess the feasibility of shielding experiments in the target hall of the GELINA facility. The main concerns were the neutron flux shape and intensity, the influence of the room return effect, and how the integral transmission coefficient would be sensitive to elastic and inelastic scattering cross sections.

From this preliminary study, it can be concluded that GELINA has the potential to perform such experiments. The total neutron emission rate is equivalent to the one that was used in the CALIBAN experiments [3]. The depleted Uranium disks available at IRMM have the suitable characteristics to obtain a targeted feedback on the plateau value of the ${ }^{238} \mathrm{U}$ inelastic cross section, with low contributions of elastic and fission cross sections for a selection of relevant dosimeters.
Other applications have been considered based on materials of interest for $4^{\text {th }}$ generation-type reactors, like ASTRID, including iron, magnesium oxide and sodium. It can be concluded that sensitivity coefficients close to unity can be reached with material thickness of $50 \mathrm{~cm}$ for $\mathrm{Fe}$ and $\mathrm{MgO}$ and $100 \mathrm{~cm}$ for $\mathrm{Na}$. An appropriate selection of different activation dosimeters with threshold energies covering the range of interest for reactor applications would provide feedback on both elastic and inelastic scattering cross sections. This would be useful to identify possible improvements on the cross sections and/or to add constraints in the evaluation process.

Additional design calculations would be required to optimize the experiment: for instance, the addition of a thin boron shelter covering the device to be irradiated would help reducing the influence of the room return effect and to get feedback on the neutron cross sections in the lower energy range (typically less than $1 \mathrm{MeV}$ ). Moreover, the analysis will have to assess the influence of the calculated neutron flux on the transmission coefficient and also the impact of angular distributions, sensitivity coefficients that will require new developments in the TRIPOLI4 Monte-Carlo code.

\section{References}

1. I. Kodelia, A. Milocco, Pedro Ortego and Enrico Sartori, 20 Years of SINBAD (Shielding Integral Benchmark Archive and Database), Progress in Nuclear Science and Technology, Volume 4 (2014) pp. 308-311.

2. A. Santamarina, P. Blaise, N. Dos Santos, C. VaglioGaudard, "Nuclear data uncertainty propagation on Power Maps", PHYSOR 2014, Kyoto, Japan, September 28 - October 3, 2014.

3. D. Bernard, P. Leconte, et al., EXCALIBUR at CALIBAN: a neutron transmission experiment for ${ }^{238} \mathrm{U}(\mathrm{n}, \mathrm{n}$ ' continuum $\gamma)$ nuclear data validation, Proceedings of the International Conference ANIMMA 2015, Lisboa (Portugal), April 2015.

4. M. Flaska, A. Borella, D. Lathouwers, L.C. Mihailescu, W. Mondelaers, A.J.M. Plompen, H. van Dam, T.H.J.J. van de Hagen, Modeling of the GELINA neutron target using coupled electronphoton-neutron transport with the MCNP4C3 code, NIM A, 531 (2004) 392-406.

5. H.A. Bethe, J.R. Beyster, and R.E. Carter, Inelastic Cross Sections for Fission Spectrum Neutrons I, II, III, IV, Journal of Nuclear Energy I, 1956 (Vol. 3), 1957 (Vol. 4).

6. G. Dejonghe, "Etude d'Effets Différentiels par la Méthode de Monte Carlo dans la Cadre de l'Equation du Transport - Applications aux calculs de protection et de neutronique," PhD. Thesis, University of Paris XI, April, 1982.

7. Perturbation Calculations by the Correlated Samples Method, Proc. of the Joint LANL - CEA Meeting on Monte Carlo Method and Applications in Neutronics, p. 311, April, 1985. 
8. A. Carlson et al., "International evaluation of neutron cross section standards", Nuclear Data Sheets 110 (2009) 3215. 